\title{
CHAPTER EIGHT ON PREDICTING HOMINID GROUP SIZES
}

\author{
JAMES STEELE
}

\section{INTRODUCTION}

Reconstructing the social systems of extinct hominids is one of the fundamental goals of palaeoanthropology and of Palaeolithic archaeology. It is also an important field of research for the many social scientists who are currently seeking to ground their models of human 'evolved behavioural predispositions' in the selective context of Pleistocene foraging bands. However, the uses of the archaeological record for this purpose are being re-evaluated, as a new generation of field workers comes to recognize the limited temporal resolution available in the archaeological record for reconstructing snapshots of Lower Palaeolithic patterns of range use, and the constraints this places on validating models like Isaac's 'home base' (Stern 1993, Lake, this volume).

Because of this, other reconstructive methodologies are urgently being sought to complement the long-term perspective which archaeology provides on human behavioural evolution. One promising field involves the use of observations of living primates to make predictions about the socioecology of extinct hominids. This is exemplified by McHenry's use of studies of sexual dimorphism in living primates to make inferences about the levels of male-male competition in hominid groups on the basis of hominid sexual size dimorphisms (this volume).

One very innovative attempt to apply this methodology to extinct hominid social systems is Aiello and Dunbar's (1993) derivation of a predictive model for fitting expected average group sizes to hominid fossils on the basis of their brain size and organization. The model is based on a bivariate regression analysis of the relationship between two variables, group size and relative neocortex size, across extant primate genera (Dunbar 1992), and uses the equation which describes a best-fit line for this covariation as a prediction equation for hominids of known cranial capacities. The strength of the original observed correlation was taken by Dunbar (1992) to indicate a causal relationship between the complexity of primate group life and the cognitive resources required by group members. Group sizes predicted for these living non-human primate genera using Dunbar's equation have a good fit with observed values $\left(\mathrm{r}^{2}=77.26\right.$, mean group size observed vs. mean group size predicted with both variables logged, $\mathrm{n}=35$ genera, data from Dunbar 1992: Table 1). Consequently, even if the hypothesis of a direct causal link is mistaken, the predictive value of the equation may remain, since any latent variables affecting both cortex ratio and average group sizes might appear to have a fairly constant effect on each variable across the primate order.

Aiello and Dunbar extend the predictive scope of this equation by interpolating steps to derive an expected 'cortex ratio' from measurements of the endocranial capacity of 
primate or hominid skulls. The arguments justifying this extension of the model are given in their paper, but without testing it against primate species of known cranial capacities and known average group sizes. In this chapter, which is conceived of as an extended footnote to their work, I shall ask four simple questions in the course of validating and extending this method of predicting behavioural variables from anatomical form. How confidently can we predict cortex ratios from endocranial capacity data? How confidently can we use the Reduced Major Axis line for predicting group size from cortex ratios? What other methods exist for deriving causal models of the relationships between anatomical and behavioural variables in living taxa? And finally, how can the accuracy of such predictive exercises be checked using archaeological evidence?

\section{HOW CONFIDENTLY CAN WE PREDICT CORTEX RATIOS FROM ENDOCRANIAL CAPACITY DATA?}

Aiello and Dunbar (1993) predicted the mean group sizes of extinct hominids, living humans and living great apes using a Reduced Major Axis equation describing the fit between generic mean group size and neocortex ratio, across thirty-five primate genera (Dunbar 1992: Eq. 1). For the fossils, neocortex ratio was predicted from estimates of total brain volume, which were in turn derived from measurements of endocranial capacity. Although the original equation correlating group size with neocortex ratio was derived from comparing generic averages, Aiello and Dunbar use it to predict specific (and intraspecific) values of the missing variable (group size) on the basis of estimates of the cortex ratios of extinct hominids of known cranial capacity. This assumes that there is no decrease in goodness-of-fit for the relationship between cortex ratio and group size when we compare congeneric species for these attributes. One simple way of testing this assumption is to take a random sample of one species from each of the genera used in the original study (Dunbar 1992), and compare the group sizes for them predicted by Aiello and Dunbar's procedure with those observed in the field.

Table 8.1 Observed and predicted group sizes for the great apes, from Aiello and Dunbar (1993)

\begin{tabular}{lllr}
\hline Genus & Brain volume $(c c)^{1}$ & Mean group size $(\text { predicted })^{2}$ & Mean group size $(\text { observed })^{3}$ \\
\hline Pan & 400,000 & 60.42 & 53.5 \\
Pongo & 397,000 & 60.11 & 2 \\
Gorilla & 469,000 & 67.2 & 7 \\
\hline
\end{tabular}

Notes

1 From Ashton and Spence (1958).

2 Predicted from Aiello and Dunbar (1993: Eqs 1, 3, 4).

3 From Dunbar (1992: Table 1) and Mackinnon (1974).

A first approximation at a test of their model is given by Aiello and Dunbar themselves 
(1993), in their use of great ape cranial capacity data from Ashton and Spence (1958) to predict average group sizes. As can be see from the fit of these predictions with observed values, this exercise is not too encouraging (see Table 8.1). Additional data on the cranial capacities of twenty-five haplorhine primate species are given in Martin (1989:362), and these have been used to derive predicted average group sizes using Aiello and Dunbar's procedure (1993: Eqs 1, 3, 4). The predicted group sizes are given in Table 8.2, with observed average group sizes extracted from the literature ${ }^{1}$. Almost all of these cranial capacity data are for species which were sampled for the generic means used by Dunbar-indeed, in sixteen cases these species were the only species sampled for their respective generic means - so it might be thought that the fit of the model would be particularly good. However, the goodness-of-fit between observed and expected group size figures as given by the coefficient of determination is poor $\left(\mathrm{r}^{2}=0.11\right.$, both variables logged). This discovery that at least 89 per cent of variation between these species in average group size was missed by the predictive model is disappointing.

A more controlled test of Aiello and Dunbar's predictive model would be to start with generic mean cranial volume data for the genera sampled in Dunbar's original paper (1992), and to loop back and predict group sizes using Aiello and Dunbar's equations (1993: Eqs 1, 3, 4). This would simply assess how much 'noise' has been introduced into the cortex ratio/group size relationship (as originally observed) by introducing extra steps into the predictive exercise, using endocranial volume rather than observed neocortex ratios as the predictor. Unfortunately, good quality endocranial volume data is not available from mature adults of all of the species sampled for Dunbar's database (i.e. the primate species represented in Stephan et al.'s data-set, 1981). Data is, however, available on total brain volumes for these species, and was used by Dunbar to derive the original predictive equation. Table 8.3 summarizes the goodness-of-fit of predicted

Table 8.2 Cranial capacity data from Martin (1989:362) used to derive group size predictions (see p. 232). Fit of observed to predicted group sizes: $r^{2}=0.11$

\begin{tabular}{lrrr}
\hline Species & $\begin{array}{l}\text { Cranial capacity } \\
(\text { cc) }\end{array}$ & $\begin{array}{l}\text { Mean group size } \\
\text { (predicted) }^{1}\end{array}$ & \multicolumn{2}{c}{$\begin{array}{c}\text { Mean group size } \\
\text { (observed) }^{2}\end{array}$} \\
\hline Tarsius spp. & 3.0 & 2.3 & 1 \\
Aotus trivirgatus & 16.9 & 7.3 & 3.8 \\
Callicebus moloch & 18.3 & 7.7 & 3.3 \\
Saimiri sciureus & 23.6 & 9.1 & 32.5 \\
Cebus apella & 76.2 & 19.9 & 13 \\
Ateles spp. & 108.8 & 25.3 & 17 \\
Lagothrix lagotricha & 97.2 & 23.5 & 23.4 \\
Alouatta seniculus & 60.3 & 17.1 & 7.1 \\
Callimico goeldii & 11.1 & 5.5 & 7.3
\end{tabular}


Cebuella pygmaea

Callithrix jocchus

Saguinus spp.

Miopithecus talapoin

Cercopithecus

ascanius

Cercocebus albigena

Macaca mulatta

Papio anubis

Theropithecus

gelada

Colobus badius

Hylobates lar

Hylobates

syndactylus

Pongo pygmaeus

Pan troglodytes

Gorilla gorilla

Homo sapiens
6.1

7.2

9.9

39.0

63.4

96.9

83.0

177.0

133.0

61.6

99.9

123.7

418.0

393.0

465.0

1409.0
3.7

4.1

5.1

12.7

17.6

23.4

21.1

35

28.9

17.3

23.9

27.6

62.2

59.7

66.8

140.2 $\mathrm{n} / \mathrm{a}$ 35

\section{Notes}

1 From Aiello and Dunbar (1993: Eqs 1, 3, 4).

2 From Dunbar (1992) and Smuts et al. (1987).

group sizes for these primate genera derived from total brain volume data (Aiello and Dunbar's Eq. 3). The fit of this predictive model is given by the coefficient of determination, $\mathrm{r}^{2}=0.34$, observed vs. predicted average group sizes (both variables logged, $n=25$ haplorhine genera, data from Dunbar 1992: Table 1). In other words, more than half of the predictive power of Dunbar's original equation linking cortex ratio and mean group sizes has been lost by introducing total brain volume as the point of extrapolation for the calculation. It may be expected that using endocranial capacity as a predictor of total brain volume has only introduced a further source of error. 
Table 8.3 Mean group sizes as predicted from total brain volume, and as observed (see p. 233). Fit of observed to predicted group sizes: $r^{2}=0.34$

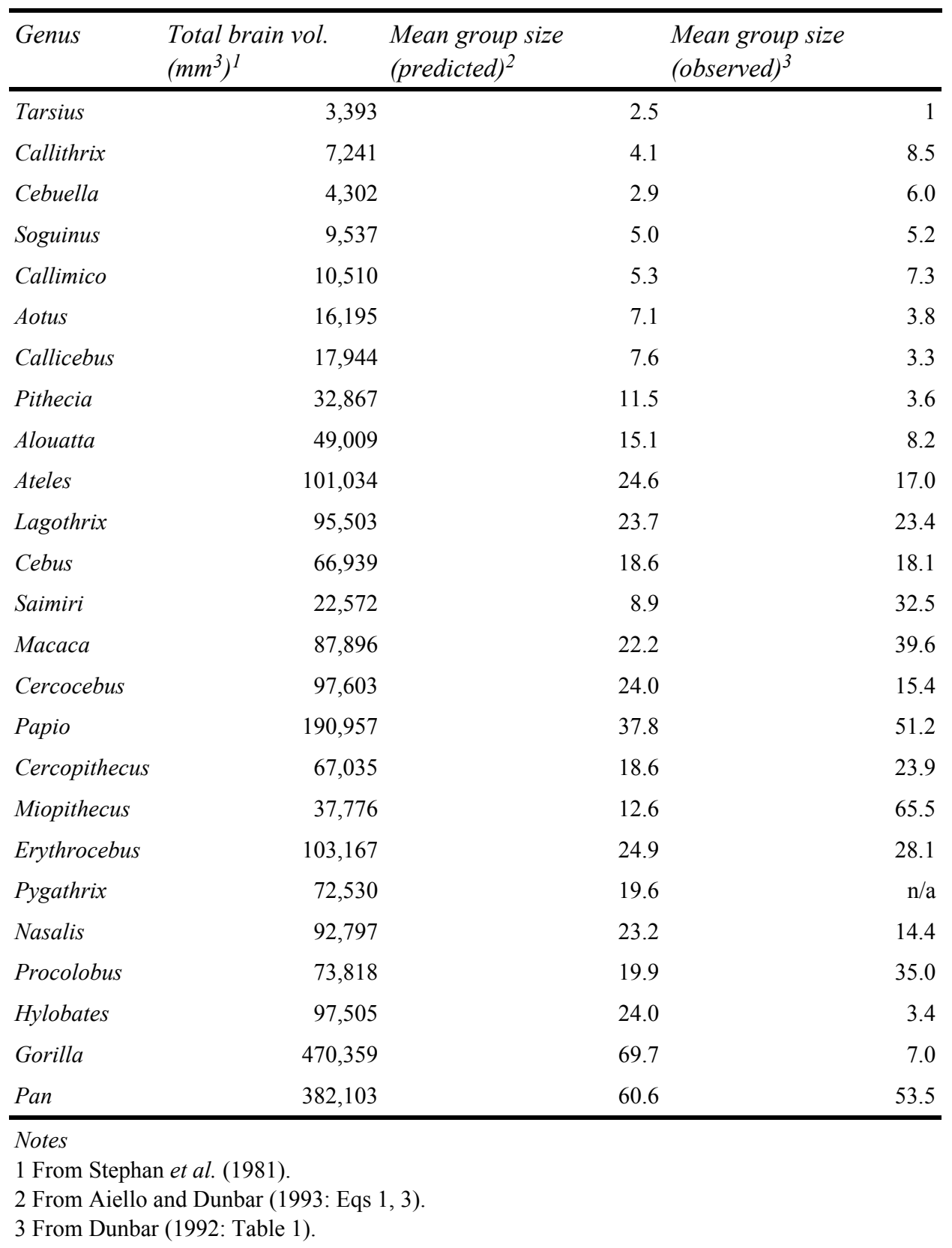


This second result makes it evident that total brain volume is a relatively poor predictor of neocortex/rest of brain ratios. This is a finding which goes against a common received view that anthropoid primates have neocortex ratios which are tightly scaled to absolute brain size at the level of interspecific or intergeneric comparisons (e.g. Passingham 1982, Deacon 1988). However, if we regress the log of Dunbar's cortex ratio for haplorhine genera (excluding Homo) against the log of total brain volume, the goodness-of-fit is less than perfect $\left(r^{2}=0.82, n=25\right.$ haplorhine genera, data in Dunbar 1992). The same is even more true if

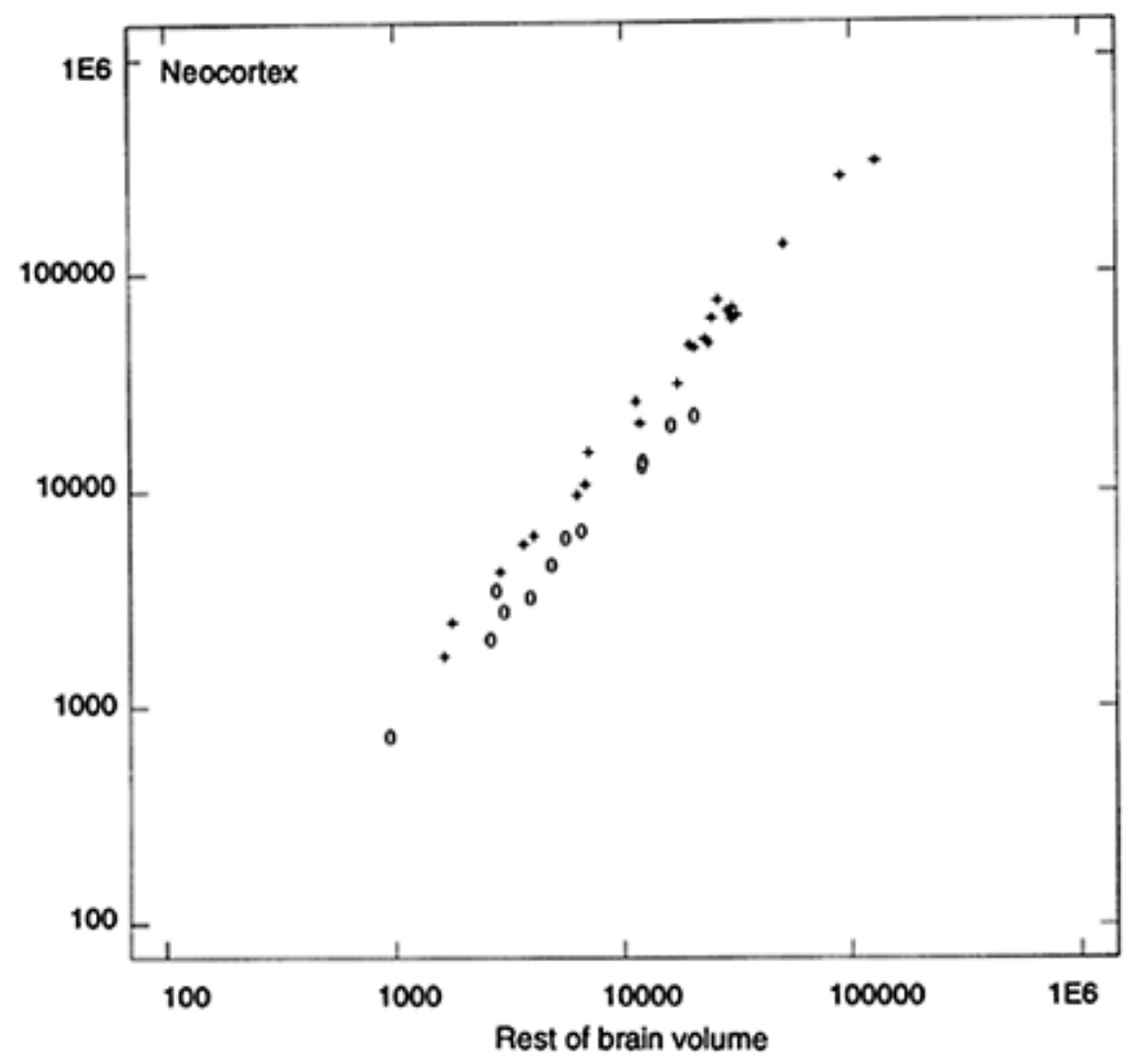

Figure 8.1 Neocortex plotted against rest of brain volume for 37 primate genera; + are haplorhines, 0 are strepsirhines (data, in $\mathrm{mm}^{3}$, are from Stephan et al. 1981)

we use the ratio of $\log$ (neocortex) to $\log$ (rest of brain volume), which is the other way to derive a cortex ratio $\left(r^{2}=0.63\right.$, alternative cortex ratio vs. total brain volume, same dataset). This is a puzzling finding, and one which requires explanation.

One possible explanation lies in the association between the brain and basal metabolic rates. The grade difference between haplorhines and strepsirhines for neocortex/wholebrain ratios, graphed by Aiello and Dunbar (1993, cf. Figure 8.1), mirrors the separation 
of primates into these two groups seen for the relationship between total neonate body weight and maternal weight, and for the relationship between cranial capacity and body weight (Martin 1989:447, 366, Armstrong 1990, cf. Figures 8.2 and 8.3). Martin (1989:449) suggests that the grade difference in relative neonate body weight between haplorhines and strepsirhines may derive from differences in maternal basal metabolic rate, while Armstrong (1990:172) shows how the grade difference in relative cranial capacity disappears when body weights are adjusted for specific metabolic rates (the amounts of $\mathrm{O}_{2}$ consumed per unit of tissue). These studies point to the possibility that variation in relative neocortex size (controlled for total brain volume) might also relate to underlying variation in metabolic rate.

We can specify a more detailed model of the specific metabolic constraints on relative neocortex size. Recent work on cerebral glucose metabolism shows that rates of glucose uptake per unit volume are considerably greater in grey matter than in white matter. This variation correlates closely with variation in the density of capillary blood vessels per unit volume. Borowsky and Collins (1989) found that in rats, grey matter has a density of capillary vessels of three to five times that found in white matter: they also found that there was a strong positive correlation between regional capillary density and glucose utilization $(\mathrm{r}=0.88, \mathrm{p}<0.001$ for data sampled across eighteen grey and five white matter sites). In the grey matter of the human cerebral cortex, it is estimated that the density of the capillary network is approximately 3.3 times that of the white matter of the hemispheres (Blinkov and Glezer 1968). Collins (1991) suggests (for the rat data) that this pattern derives from the higher firing rates of synapses which characterize the resting or control state in these more densely vascularized areas of the brain.

Armstrong (1985) has shown that brain size scales isometrically to available metabolic energy (body mass $\times$ specific basal metabolic rate), with a slope very close to 1.0 across mammal species. The same is true for neocortical sheet surface area in primates. This can be demonstrated if we take the slopes of the two Reduced Major Axis lines fitted to the generic mean neocortex/rest-of-brain data for strepsirhines and haplorhines (Figure 8.1), as given by the following regression equations (all data from Stephan et al. 1981).

For strepsirhines ( $\mathrm{n}=12$ genera):

$$
\begin{aligned}
& \log _{10} \text { Neocortex }\left(\mathrm{mm}^{3}\right)= \\
& -0.460+1.125\left(\log _{10} \text { Rest of Brain, } \mathrm{mm}^{3}\right) \cdot \mathrm{r}^{2}=0.985 .
\end{aligned}
$$

For haplorhines ( $\mathrm{n}=25$ genera, excl. Homo):

$$
\begin{aligned}
& \log _{10} \text { Neocortex }\left(\mathrm{mm}^{3}\right)= \\
& -0.523+1.20\left(\log _{10} \text { Rest of Brain, } \mathrm{mm}^{3}\right) \cdot \mathrm{r}^{2}=0.992 .
\end{aligned}
$$

In mammals with convoluted neocortices, total cortical surface area scales to total volume of gray matter to the power of 0.89 , while total volume of gray matter scales to total neocortical volume to the power of 0.933 (Hofman 1989). Thus neocortical surface area scales to neocortex 


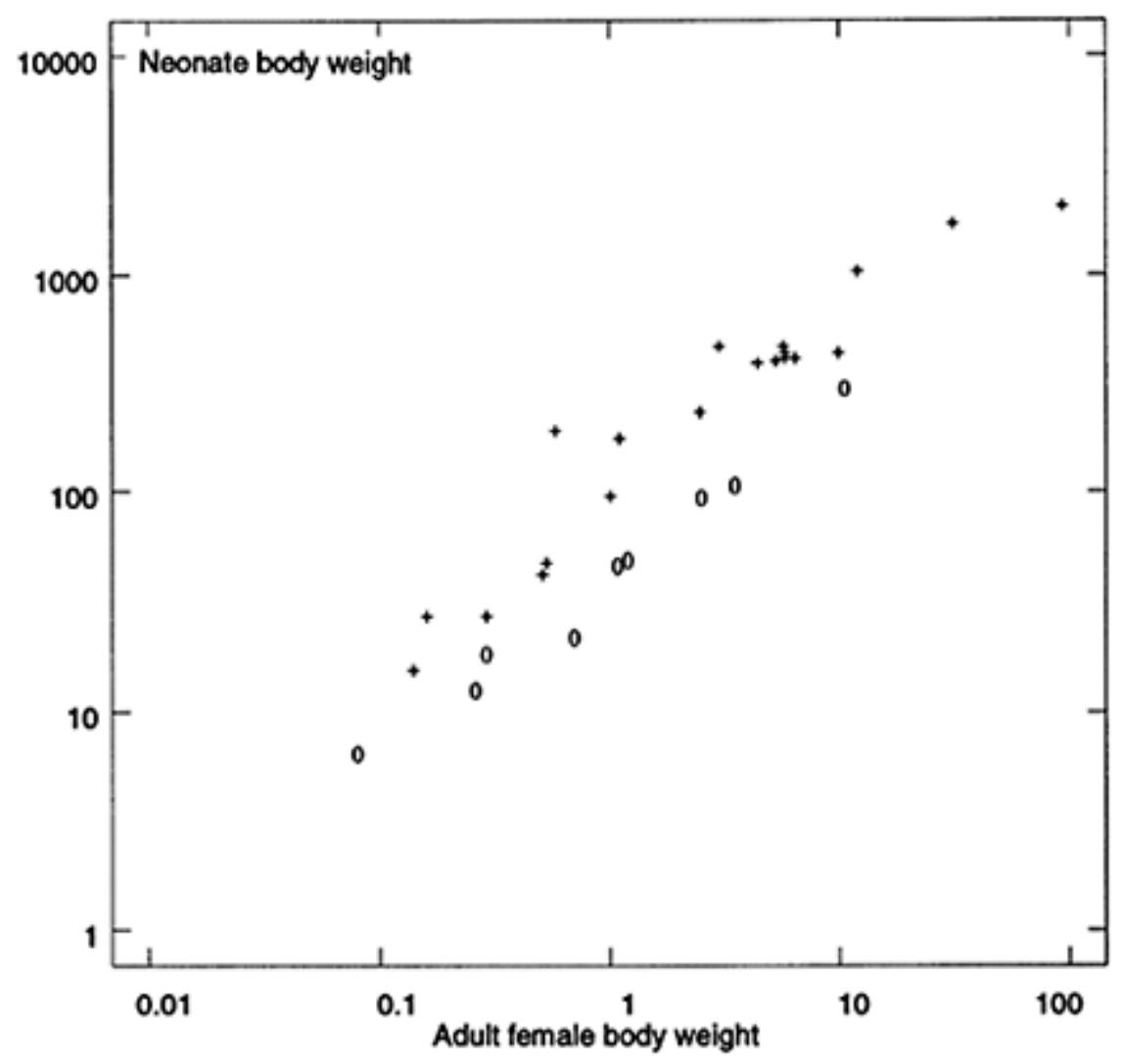

Figure 8.2 Neonate body weight (g) plotted against female adult body weight $(\mathrm{kg})$ for 32 primate genera; + are haplorhines, 0 are strepsirhines (data from Harvey et al. 1987)

volume to the (compounded) power of 0.83 . Since neocortex volume scales to the rest of the brain to the powers of 1.12 (strepsirhines) and 1.20 (haplorhines), we can derive the observation that for haplorhines, at any rate, neocortical surface area - an index of the proportion which is the metabolically expensive grey matter - scales isometrically with total brain volume $(1.20 \times 0.83=0.996)$. The scaling factor for strepsirhines is 0.93 .

Because of the characteristic folded, 'gyrified' pattern of neocortical grey matter, which evidently represents an adaptation of this structure to the constraints of a quasispherical endocranial space under selection for optimization of sheet surface area, the ratio of superficial grey to white matter in this area can be expected to decrease with size less markedly than in other, non-convoluted brain structures (the only close parallel is with the cerebellum, which appears in fact closely to track the neocortex 


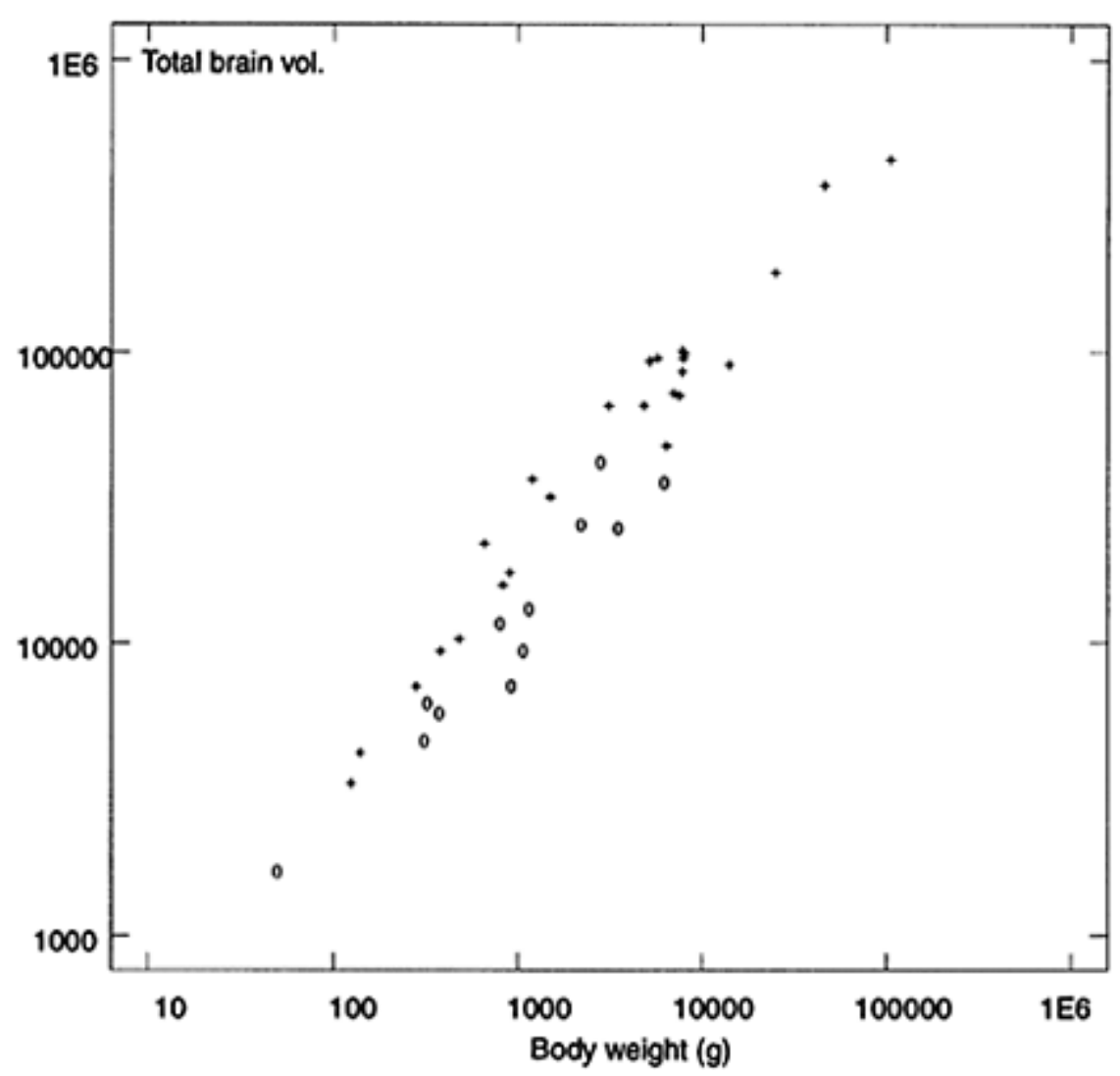

Figure 8.3 Total brain volume $\left(\mathrm{mm}^{3}\right)$ plotted against body weight $(\mathrm{g})$, for 37 primate genera; + are haplorhines, 0 are strepsirhines (data from Stephan et al. 1981)

in its volume scaling ratios). This means that an increase in the relative size of the neocortex (controlled for total brain volume) will incur an increase in the total metabolic needs of the brain. It follows that neocortex size and cerebellum size (relative to total brain volume) should co-vary with the overall capacity of the organism to deliver oxygen and glucose to the brain (which, following Armstrong 1990, we expect to be a function of body size and specific basal metabolic rate). This leads us to a testable 'metabolic constraints' hypothesis of the variance in the cortex ratio-total brain volume relationship, which has so drastically reduced the predictive power of Dunbar's original group size/cortex ratio equation. As has been shown to be the case for total brain volume in mammals (Armstrong 1985), the neocortex ratio is expected to scale isometrically to available metabolic energy, calculated as the product of body mass and specific basal metabolic rate (sBMR). Cases such as Gorilla, which have large bodies, but not especially great relative brain size or cortex ratio, would be expected to also have a relatively low specific BMR. 
It is worth noting here that residual variation in neocortex size (controlled for brain size) shows some degree of correlation with relative brain size (controlled for body size). In both cases, residuals for non-human haplorhines were derived as the distance from a datum to a point perpendicular to it on the Reduced Major Axis line, as suggested by Martin and Barbour (1989).

The following are the Reduced Major Axis lines used for this exercise, and the equation used to derive values for the residuals:

$$
\log _{10} \text { Neocortex Ratio }=-0.61+0.20\left(\log _{10} \text { Total Brain Volume, } \mathrm{mm}^{3}\right)
$$

$\left(\mathrm{r}^{2}=81.6, \mathrm{n}=25\right.$ non-human haplorhine genera, data in Stephan et al. 1981$)$

$$
\log _{10} \text { Total Brain Volume }\left(\mathrm{mm}^{3}\right)=2.102+0.735\left(\log _{10}\right. \text { Body Weight, g) }
$$

$\left(\mathrm{r}^{2}=96.3\right.$, data as for Eq. 3$)$

$$
\text { For } \left.\mathrm{i}=1 \ldots \mathrm{n}, \mathrm{L}_{\mathrm{i}} \text { (residual }\right)=\left(\mathrm{y}_{\mathrm{i}}-\mathrm{a}-\mathrm{bx_{i } )} \sqrt{\frac{\sum\left(x_{\mathrm{i}}-\dot{\mathrm{x}}\right)^{2}}{\sum\left(y_{i}-\dot{\mathrm{y}}\right)^{2}+\sum\left(x_{i}-\hat{x}\right)^{2}}}\right.
$$

(where $\mathrm{a}$ and $\mathrm{b}$ are respectively the intercept and the slope coefficient of the RMA equation).

Results are given in Table 8.4. Of the five genera with the greatest negative residual variation from the neocortex ratio/total brain volume line, four also made up the group with the greatest negative residual variation from the total brain volume/body mass line (Alouatta, Gorilla, Nasalis and Tarsius). Contrariwise, Saimiri and Miopithecus were among the three genera with the greatest positive residual variation from both these lines. If these two sets of genera were also distinguished by their contrastive relative BMRs, it would support the suggestion that cortex ratio variation is subject to metabolic energy constraints. Low sBMR species will have brains with relatively little of the grey-matter intensive, metabolically expensive neocortex, while high sBMR species will be able to 'afford' both encephalization, and a higher proportion of neocortex than their brain size would lead us to expect.

Saimiri is, in fact, the only primate for which good resting metabolism data is available which has a relatively high BMR for its size (compared with the general mammal trend) (Ross 1992). There is some reason to expect this to be the case for Miopithecus too, since in addition to the relatively large brain and high cortex ratio, this species has a fairly high ratio of neonate to maternal body weight (Napier and Napier 1985), 
Table 8.4 Residuals analysis, using data from Stephan et al. (1981) and Dunbar (1992); values for Homo also interpolated (see p. 239)

\begin{tabular}{|c|c|c|c|}
\hline Genus & $\begin{array}{l}\text { Residuals (cortex ratio, } \\
\text { controlled for total brain } \\
\text { volume) }\end{array}$ & Genus & $\begin{array}{l}\text { Residuals (total brain } \\
\text { volume, controlled for body } \\
\text { weight) }\end{array}$ \\
\hline Saimiri & 0.090 & [Homo] & {$[0.356]$} \\
\hline Erythrocebus & 0.087 & Miopithecus & 0.170 \\
\hline Miopithecus & 0.069 & Saimiri & 0.144 \\
\hline Cebuella & 0.045 & Cebus & 0.126 \\
\hline Macaca & 0.045 & Lagothrix & 0.118 \\
\hline Cercopithecus & 0.040 & Hylobates & 0.101 \\
\hline Saguinus & 0.029 & Pithecia & 0.064 \\
\hline Callithrix & 0.027 & Pan & 0.042 \\
\hline Callimico & 0.018 & Erythrocebus & 0.040 \\
\hline [Homo] & [0.015] & Ateles & 0.026 \\
\hline Pan & 0.012 & Cerocebus & 0.018 \\
\hline Cebus & 0.009 & Cercopithecus & 0.012 \\
\hline Papio & 0.004 & Saguinus & 0.015 \\
\hline Cercocebus & -0.002 & Macaca & -0.016 \\
\hline Procolobus & -0.008 & Collicebus & -0.016 \\
\hline Ateles & -0.011 & Aotus & -0.031 \\
\hline Callicebus & -0.016 & Callithrix & -0.033 \\
\hline Aotus & -0.022 & Cebuella & -0.037 \\
\hline Lagothrix & -0.029 & Callimico & -0.042 \\
\hline Pithecia & -0.035 & Papio & -0.044 \\
\hline Pygathrix & -0.040 & Procolobus & -0.049 \\
\hline Tarsius & -0.053 & Pygathrix & -0.073 \\
\hline Nasalis & -0.055 & Tarsius & -0.091 \\
\hline Alouatta & -0.057 & Gorilla & -0.098 \\
\hline Hylobates & -0.060 & Nasalis & -0.147 \\
\hline Gorilla & -0.089 & Alouatta & -0.169 \\
\hline
\end{tabular}

which Martin (1989) suggests may be a marker of high relative BMR. Contrariwise, Gorilla, which has relatively small brain size and low cortex ratio, and also has a 
relatively low ratio of neonatal to maternal body weight (Martin and Maclarnon 1988), is expected on ecological grounds to have a low relative BMR (Ross 1992:19).

Interestingly, Saimiri and Miopithecus are also among the three haplorhine genera for which group size is most underestimated by Dunbar's equation, while Gorilla is the genus for which the equation most overestimates the parameter (cf. Table 8.5-residual deviation of observed mean group size from that predicted by Dunbar 1992: Eq. 1). Saimiri and Miopithecus are small-Saimiri is the smallest New World cebid monkey, Miopithecus is the smallest Old World monkey - and they have both been

Table 8.5 Residuals from the predicted group sizes from Dunbar's Equation 1 (1992)

\begin{tabular}{|c|c|}
\hline Genus & Residuals (group size, controlled for cortex ratio using Dunbar's Eq. 1) \\
\hline Miopithecus & 0.137 \\
\hline Procolobus & 0.079 \\
\hline Saimiri & 0.072 \\
\hline Callithrix & 0.062 \\
\hline Cebuella & 0.044 \\
\hline Papio & 0.035 \\
\hline Logothrix & 0.029 \\
\hline Macaca & 0.028 \\
\hline Callimico & 0.021 \\
\hline Nasalis & -0.004 \\
\hline Cercopithecus & -0.008 \\
\hline Cebus & -0.011 \\
\hline Alouatta & -0.018 \\
\hline Saguinus & -0.024 \\
\hline Pan & -0.025 \\
\hline Ateles & -0.034 \\
\hline Cercocebus & -0.052 \\
\hline Aotus & -0.057 \\
\hline Tarsius & -0.062 \\
\hline Erythrocebus & -0.069 \\
\hline Callicebus & -0.088 \\
\hline Pithecia & -0.109 \\
\hline Hylobates & -0.181 \\
\hline Gorilla & -0.194 \\
\hline
\end{tabular}


observed in very large groups of up to 200 individuals. According to Napier and Napier (1985), they both have complex social systems subdivided into adult male bands, motherinfant bands and juvenile bands, and the closest parallels for each is with the other, rather than with a more closely genetically related species. Gorilla, Hylobates, Pithecia and Tarsius are among the seven genera which have greatest negative residual deviation of neocortex ratio from total brain volume, and also among the six genera which have the greatest proportional 'underperformance' on group size compared with that predicted from their neocortex ratio using Dunbar's equation. The implication is that investment in a higher or lower proportion of the metabolically costly neocortex may co-vary with group size, perhaps due to the effect of some confounding variable - probably dietary quality and abundance - affecting both sBMR and the cost/benefit balance of larger feeding aggregations.

These analyses have shown that the variance in the brain size/cortex ratio relationship, which causes a 50 per cent loss in predictive power for Dunbar's group size equation when brain size is used, can be explained in part by a model of energetic constraints affecting corticalization. How much does this observation affect Aiello and Dunbar's group size predictions for extinct hominids? In Table 8.4 I have interpolated figures for the residual deviation of Homo sapiens sapiens' brain volume and cortex ratio from the lines fitted to non-human haplorhine brain and body size data (Homo was omitted from the original calculations due to claims that Homo is anomalous among haplorhines in the cortex ratio, Deacon 1988). It will be seen that modern human anatomy makes Homo an extreme outlier for brain/body size, but not an outlier in terms of neocortex ratio. Humans also have a basal metabolic rate which is fairly normal for body weight among haplorhines. This suggests that predictions of cortex ratio from absolute brain size in fossil hominid taxa will not be hopelessly wide of the mark, and will likely err on the side of underestimation. However, the cumulative error attaching to these calculations makes the specific group size predictions of Aiello and Dunbar for Australopithecus and Homo (including Homo sapiens sapiens) unreliable other than as broad indicators of a tendency in hominid social system evolution. It seems, then, that we can use endocranial capacity data to predict cortex ratios with only a limited degree of confidence.

\section{HOW CONFIDENTLY CAN WE USE THE REDUCED MAJOR AXIS LINE FOR PREDICTING GROUP SIZE FROM CORTEX RATIOS?}

Another question mark attaching to such group size predictions concerns the use of Reduced Major Axis line equations in predicting missing values of the $\mathrm{Y}$-variable (see also Smith 1994). Prediction in regression analysis is usually done using the least-squares model, since in this model error variance is restricted to the dependent variable. Values of the dependent variable can therefore be predicted from the known value of the independent variable, to a confidence interval specified from analysis of the error variance in the original data for the dependent variable. With the reduced major axis, however, error is supposed to be distributed equally in both variables, with the consequence that the fitted line usually has a significantly steeper slope than that fitted by the least-squares method. However, no procedure exists for attaching a confidence 
interval to estimates of the $\mathrm{Y}$-variable derived from observed values of the $\mathrm{X}$-variable in the Reduced Major Axis model. Some heuristic estimates of the confidence interval for the slope and intercept parameters exist: Draper (1992) suggests that the two leastsquares regression slopes ( $\mathrm{Y}$ on $\mathrm{X}$, and $\mathrm{X}$ on $\mathrm{Y}$, appropriately transformed) might be taken as approximate indicators of the confidence interval for the slope, while Davis (1986:204, Eqs 4.45 and 4.47) gives formulae for the standard errors of the intercept and slope for the reduced major axis line which can be used to determine an approximate confidence interval around these values. As an approximate guide to the confidence interval for the intercept and slope of Dunbar's original cortex ratio/group size equation (1992: Eq. 1) I have used both these methods. The results for the least-squares method (Draper 1992:9) put outer limits for the intercept at 0.177-0.012, and for the slope as 2.96-3.86, while calculation of the standard error for the same parameters using Davis' method gives a range for the intercept of $0.29-0.215$, and for the slope of 3.11-3.67. But these confidence intervals for the RMA line parameters cannot be used to derive confidence intervals for predictions. As Janson (1993) points out, if conventional leastsquares regression had been used to predict an average group size for humans, the 95 per cent confidence interval would cover the range 23-446 individuals! So we can use the RMA line for prediction with only very limited confidence, pending further work on the methodology. It is evident that this aspect of allometric analysis needs further attention if we are to undertake predictive modelling based on RMA line-fitting.

\section{WHAT OTHER METHODS EXIST FOR DERIVING CAUSAL MODELS OF THE RELATIONSHIPS BETWEEN ANATOMICAL AND BEHAVIOURAL VARIABLES IN LIVING TAXA?}

We have seen that there are problems in predicting hominid average group sizes from cortex ratios, due partly to the difficulty in reliably estimating cortex ratios of individuals of extinct species for whom only endocranial capacity data is available, and partly to the limitations of the Reduced Major Axis model as a prediction equation. Although the problem of the lack of a confidence interval for RMA predictions remains, the variables used in the prediction equation can be varied to try to increase the fit of observed to estimated Y-values for living primates, using anatomical data which can be recovered from fossils.

In this section, I shall outline an alternative prediction equation for estimating hominid average group size. The model is that of multiple regression. Multiple regression analysis of the data set in Table 8.6 (cf. Figure 8.4) suggests that average group size can be predicted (albeit with limited reliability) from a combination of adult female body weight and adult total brain volume data (multiple $\mathrm{R}^{2}=0.59$ ). This is not surprising, since our analyses have shown that cortex ratio (which is an even stronger predictor of group size) varies both with total brain volume and with relative brain size (relative both to body size and to maternal body weight). The multiple regression equation for this model, calculated by the least squares method, is as follows: 


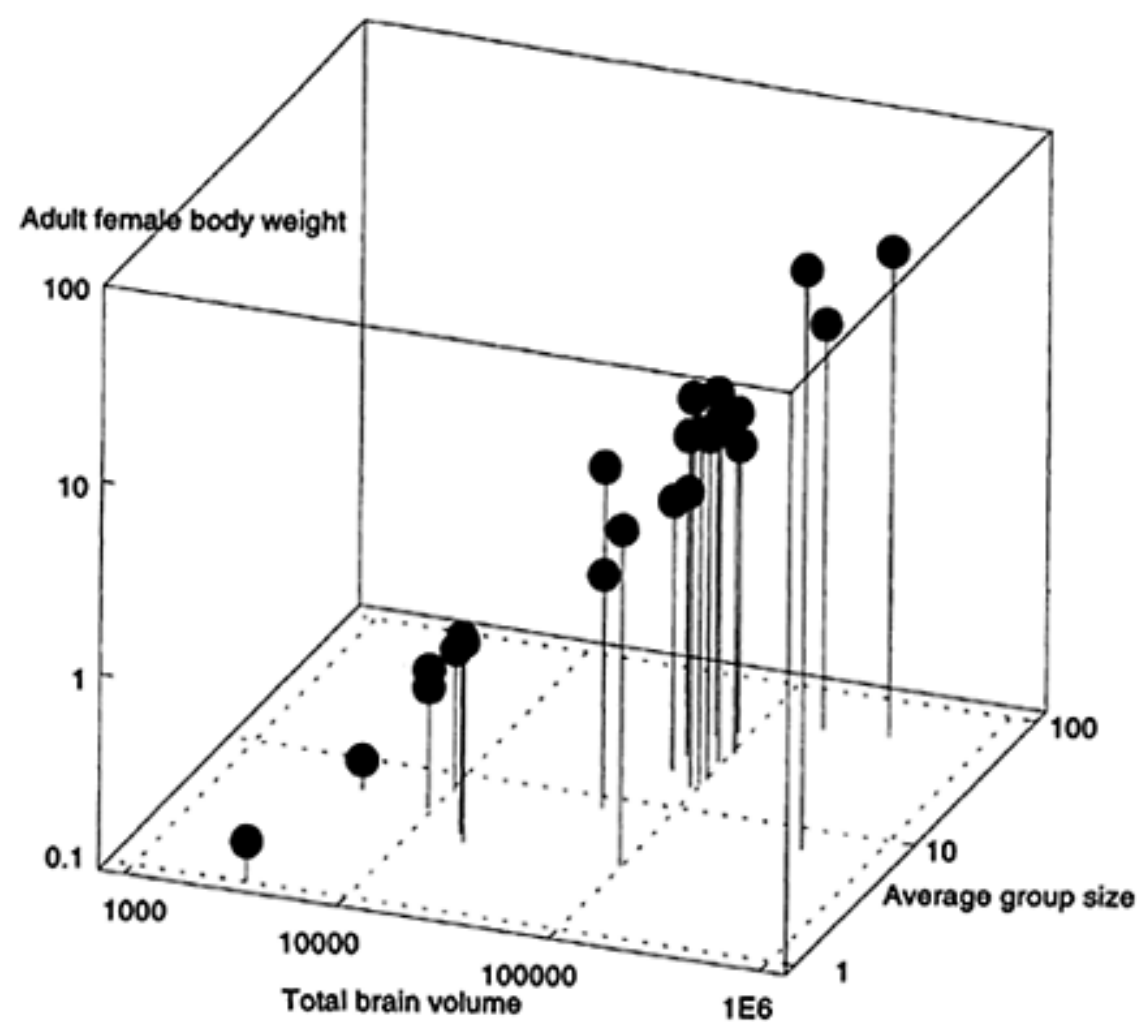

Figure 8.4 Scatterplot of data on female adult body weight $(\mathrm{kg})$, total brain volume $\left(\mathrm{mm}^{3}\right)$ and average group size for 25 haplorhine genera (data in Table 8.6)

\section{$\log _{10}$ Mean Group Size $=-8.525+2.20 \log _{10}$ Total Brain Vol. $\left(\mathrm{mm}^{3}\right)$ $-1.45 \log _{10}$ Adult Female Body Weight (kg).

This gives a fit of $\mathrm{r}^{2}=0.63$ between predictions and the observed haplorhine group sizes in Dunbar's data set, which is a marked improvement on the fit of Aiello and Dunbar's model derived from total brain volume alone (observed/predicted haplorhine group sizes, $r^{2}=0.34$, see p. 233). It will be seen that the fit for the apes is still not perfect, although Gorilla has become separated out by its predicted small group size. Parenthetically, we may also record that if the partial regression coefficients for the slopes of the predictor variables in Eq. 6 had been derived from RMA line-fitting for the underlying bivariate regressions, the correlation of the predicted and observed haplorhine group sizes would have been much worse $\left(r^{2}=0.35\right)$, suggesting that in this case more of the error 
Table 8.6 Data and predictions for average group sizes of 25 living haplorhine genera from my Equation 6 (see p. 244). Generic means are for species for which total brain volume data was available. Values for Homo interpolated. The $\mathrm{r}^{2}$ for the correlation between observed and predicted group sizes is 0.63

\begin{tabular}{|c|c|c|c|c|}
\hline Genus & $\begin{array}{l}\text { Female adult } \\
\text { mass }(\mathrm{kg})^{1}\end{array}$ & $\begin{array}{l}\text { Total brain vol. } \\
\left(\mathrm{mm}^{3}\right)^{2}\end{array}$ & $\begin{array}{l}\text { Mean group size } \\
\text { (predicted by Eq. 6) }\end{array}$ & 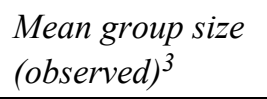 \\
\hline Tarsius & 0.16 & 3,393 & 2.5 & 1.0 \\
\hline Callithrix & 0.29 & 7,241 & 5.6 & 8.5 \\
\hline Cebuella & 0.14 & 4,302 & 5.1 & 6.0 \\
\hline Soguinus & 0.51 & 9,537 & 4.5 & 5.2 \\
\hline Callimico & 0.53 & 10,510 & 5.3 & 7.3 \\
\hline Aotus & 1.0 & 16,195 & 5.4 & 3.8 \\
\hline Callicebus & 1.05 & 17,944 & 6.4 & 3.3 \\
\hline Pithecia & $\mathrm{n} / \mathrm{a}$ & 32,867 & $\mathrm{n} / \mathrm{a}$ & 3.6 \\
\hline Alouatta & 5.7 & 49,009 & 5.0 & 8.2 \\
\hline Ateles & 5.8 & 101,034 & 23.9 & 17.0 \\
\hline Lagothrix & 5.8 & 95,503 & 21.1 & 23.4 \\
\hline Cebus & 2.47 & 66,939 & 33.3 & 18.1 \\
\hline Saimiri & 0.58 & 22,572 & 24.9 & 32.5 \\
\hline Macaca & 3.0 & 87,896 & 45.7 & 39.6 \\
\hline Cercocebus & 6.4 & 97,603 & 19.2 & 15.4 \\
\hline Papio & 12.0 & 190,957 & 33.7 & 51.2 \\
\hline Cercopithecus & 4.4 & 67,035 & 14.4 & 23.9 \\
\hline Miopithecus & 1.1 & 37,776 & 30.5 & 65.5 \\
\hline Erythrocebus & 5.6 & 103,167 & 26.3 & 28.1 \\
\hline Pygathrix & $\mathrm{n} / \mathrm{a}$ & 72,530 & $\mathrm{n} / \mathrm{a}$ & $\mathrm{n} / \mathrm{a}$ \\
\hline Nasalis & 9.9 & 92,797 & 9.1 & 14.4 \\
\hline Procolobus & 5.8 & 73,818 & 12.0 & 35.0 \\
\hline Hylobates & 5.3 & 97,505 & 25.2 & 3.4 \\
\hline Gorilla & 93.0 & 470,359 & 12.6 & 7.0 \\
\hline Pan & 31.1 & 382,103 & 39.0 & 53.5 \\
\hline [Homo] & [40.1] & {$[1,251,847]$} & [367.3] & {$[\mathrm{n} / \mathrm{a}]$} \\
\hline
\end{tabular}

Notes 
1 From Harvey et al. (1987).

2 From Stephan et al. (1981).

3 From Dunbar (1992).

variance is contained in the behavioural than the anatomical observations (see also Smith 1994).

In Table 8.7 a sample of hominid taxa are listed with their estimated female body weights, total brain volumes, and with average group sizes as predicted from my Equation 6 and from Aiello and Dunbar's equations (1993). The cumulative error likely in the derivations of total brain volume

Table 8.7 Data and predictions for average group sizes of various fossil hominid taxa, ${ }^{1}$ using predictive equations from Aiello and Dunbar (1993) and Steele

(Equation 6)

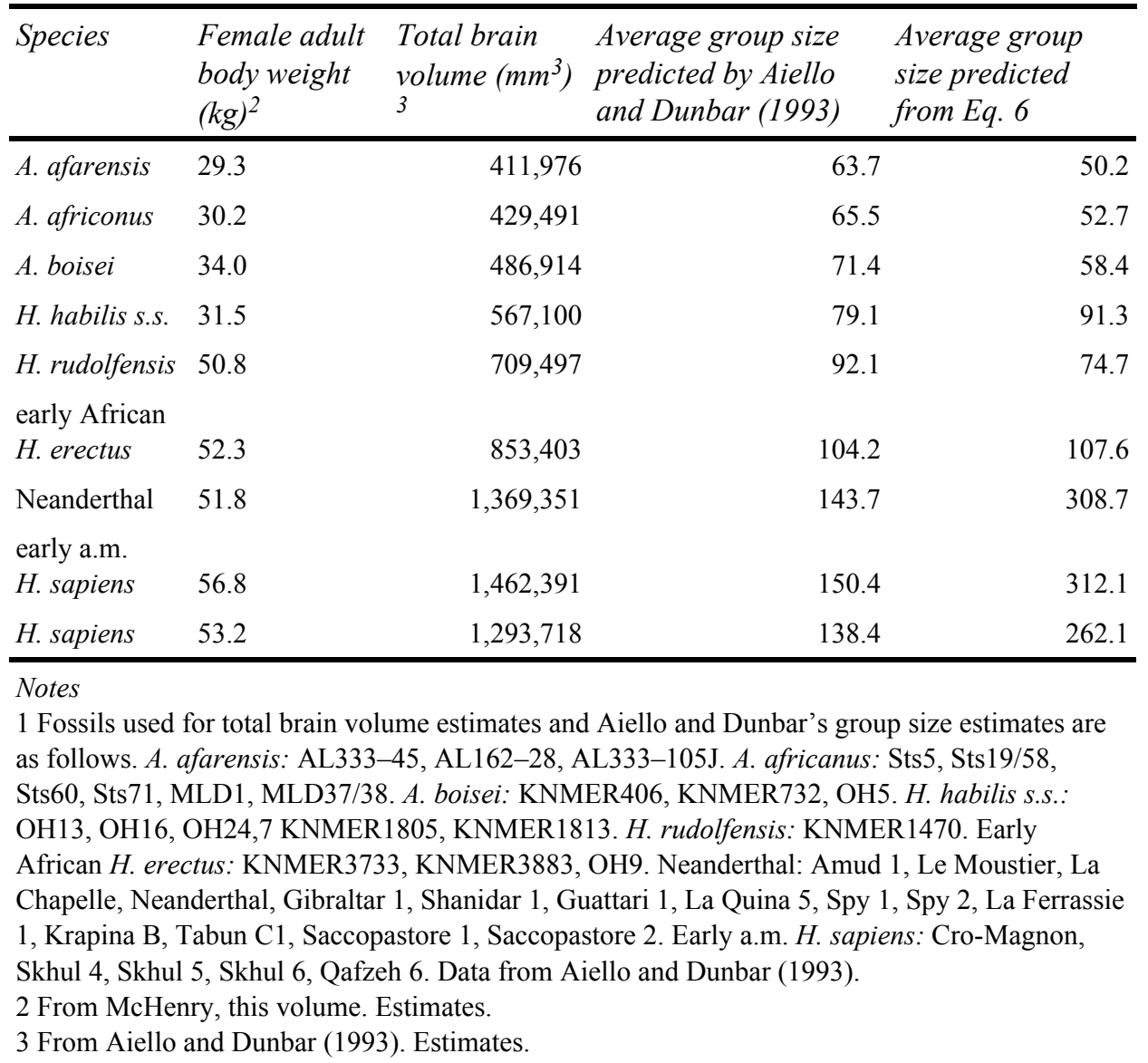


and body weight estimates for the fossil hominids suggests that they should be used only as illustrations of the differences the use of the new prediction equation makes. However, it will be apparent that use of Equation 6 has markedly affected the predictions for group sizes for Neanderthals and Homo sapiens. Indeed, this predictive model would support a 'late spurt' account of hominid social system evolution, whereas Aiello and Dunbar's predictions (1993) were used to support a gradualist account.

This does not necessarily invalidate Dunbar's use of the cortex ratio to predict a group size of 148 for modern Homo sapiens (Dunbar 1993, this volume). After all, my new equation responds to problems with predictions for haplorhine genera with large residual deviations from the neocortex/ total brain volume scaling trend, and this is not a problem either for Pan or for Homo. Group sizes predicted from hominid endocranial volumes are therefore less likely to be subject to such sources of error than would be predictions from skull volumes of (for instance) extinct saimirids, or of ancestral apes like Sivapithecus or Proconsul. It does, however, illustrate the uncertainty attaching to such predictions when outlier values are used as predictors, since the average group size predicted for humans by my Equation 6 (which uses total brain volume and adult female body weight as predictor variables) is about twice that predicted from neocortex ratio by Dunbar using his Equation 1 (1992). In fact, if (for consistency with the living primate genera) we use Harvey et al.'s (1987) datum for human adult female body weight, and Stephan et al.'s (1981) datum for human total brain volume, then we get an alternative, even greater prediction from Equation 6 of an average human group size of 367 (see Table 8.6). The difference between this figure and that of 262 given in Table 8.7 reflects the sensitivity of Equation 6 to variation in estimates of mean human adult female body mass. By way of complete contrast Martins (1993), who used least squares regression to predict human mean group size from neocortex ratio, derived a prediction for Homo of 42.9. The differences hang on the statistical line-fitting technique used and the method used to factor out phylogenetic constraints.

\section{CONCLUSIONS REGARDING THE PREDICTION MODELS}

In this chapter, I have taken the view that regression equations describing strong correlations between anatomical and behavioural variables in living primates have the potential to be used as prediction equations for missing values of the behavioural variable in extinct hominid taxa. The attempt to infer average group sizes from the relative size of the neocortex is an example of such predictive modelling. As has been shown, there are pitfalls in the inference of cortex ratio from endocranial capacity in haplorhines which hinder this project, although this represents a tractable problem: some of the variance in the neocortex/brain volume relationship may relate to variance in total metabolic energy budgets between primates of the same body size.

Additionally, there is considerable variance in the average group sizes of living primate genera which is not accounted for either by the neocortex ratio or by the joint effects of brain size and female body mass, and this further complicates the predictive exercise. Because of this, it seems that group sizes cannot yet be predicted for extinct hominids with any great degree of certainty, even within a fairly wide confidence interval. 
However, progress has already been made to improve the models predictive accuracy, both here and elsewhere (cf. Dunbar 1993 with peer commentaries). In part such development must come from a closer look at the data from which average group size estimates for the living primates were derived. This case looks like a good 'laboratory' for evaluating the use of predictive equations derived from primate allometry, and we may hope for continuing improvement in our understanding of the causal structure of the brain-social system relationship in primates, and of its implications for reconstructing the lifeways of our hominid predecessors.

\section{TOWARDS ARCHAEOLOGICAL TESTS OF HOMINID GROUP SIZE PREDICTIONS}

In his response to peer commentaries on an earlier paper, Dunbar (1993:725) challenged that archaeological evidence suggesting prehistoric forager groups were of the order of 25-50 people is uninformative, since it tells us nothing about the possible higher levels of integration which may have characterized these Palaeolithic societies. As we have seen, however, different techniques result in very different predictions of human and hominid group sizes: Martins (1993) predicts ancestral human groups of the scale of the foraging local band (25-50 persons); Dunbar (1993) predicts groups on the scale of an intermediate level of integration between the minimum and the maximal band (c. 125150 persons); and my own equation predicts groups on the scale approximating to the human foragers' maximal band (c. 300 persons). Clearly there is a need for independent sources of evidence which would enable us to test the validity of these varying predictions. Dunbar's strategy is to take a theoretically derived number for human group sizes, and to search the social scientific literature for confirmation that this number represents an empirical limit on grouping patterns of a certain level of integration. This is a wholly valid procedure. My alternative strategy here is to take theoretically derived numbers, and to search the archaeological record for new means of confirmation that they do or do not represent limits on hominid and early modern human grouping patterns.

The archaeological evidence most often used to estimate group sizes is site area and number of hearths, used to predict the size of the bands using the site on the basis of equations describing the relationship between settlement area and group size in modern foraging societies. Thus Hassan (1981:93) gives such estimates of the forager band sizes inhabiting sites from the basal Pleistocene (FlK1, Olduvai) to the early Holocene (Kebaran, Natufian) which converge on an average estimate of about 20 persons (range 1-48, excluding large sites from the Natufian). Dunbar's objection, quite rightly, is that there may be higher levels of spatial integration which existed in the Palaeolithic but which have left no archaeological trace (see also Gamble, this volume).

Site area is not, however, the only potential source of archaeological evidence. Raw material transport is an indicator of the minimum diameters of home ranges, and home range area scales to group mass (the total biomass of a social group of animals) with a fairly tightly correlated positive relationship in mammals (Grant et al. 1992), such that it is possible to predict the diameter of an idealized circular home range where the area (in square kilometres) has been derived from prediction equations from group mass. Adult 
body weight estimates have been given for the Hominidae by McHenry (1994, this volume). Group mass can be worked out for a given group size if (following CluttonBrock and Harvey 1977) we assume group composition with a ratio of one male : one female : two juveniles, and a mean body weight for juveniles of half the mean adult body weight. We can therefore predict home range diameters for the various members of the hominid series for given group sizes, and test these predictions against the maximum distances of raw material transport found in the archaeological record associated with these fossil taxa (Table 8.8, see also Gamble and Steele, in prep.).

Foley (1987) has pointed out that the home range sizes indicated by lithic transport distances at Olduvai Gorge, and associated with the earliest

Table 8.8 Group mass and home range diameter for selected hominid species. Body weight data from McHenry, this volume. Prediction equations for home range areas of primates and for carnivores with undefended ranges from Grant et al. (1992: Figures 3, 5)

\begin{tabular}{|c|c|c|c|c|}
\hline Species & $\begin{array}{l}\text { Group } \\
\text { size }\end{array}$ & $\begin{array}{l}\text { Group } \\
\text { mass (kg) }\end{array}$ & $\begin{array}{l}\text { Home range diameter } \\
(\mathrm{km}) \text {, primate model }\end{array}$ & $\begin{array}{l}\text { Home range diameter } \\
(\mathrm{km}) \text {, carnivore model }\end{array}$ \\
\hline $\begin{array}{l}\text { H. hobilis } \\
\text { s.s. }\end{array}$ & 25 & 642 & 3.0 & 26.2 \\
\hline $\begin{array}{l}\text { H. habilis } \\
\text { s.s. }\end{array}$ & 125 & 3,211 & 5.9 & 53.2 \\
\hline $\begin{array}{l}\text { H. hobilis } \\
\text { s.s. }\end{array}$ & 300 & 7,706 & 8.5 & 78.0 \\
\hline $\begin{array}{l}\text { H. } \\
\text { rudolfensis }\end{array}$ & 25 & 1,035 & 3.6 & 32.4 \\
\hline $\begin{array}{l}\mathrm{H} . \\
\text { rudolfensis }\end{array}$ & 125 & 5,175 & 7.2 & 65.5 \\
\hline $\begin{array}{l}\text { H. } \\
\text { rudolfensis }\end{array}$ & 300 & 12,420 & 10.4 & 96.2 \\
\hline $\begin{array}{l}\text { early African } \\
\text { H. erectus }\end{array}$ & 25 & 1,078 & 3.7 & 32.9 \\
\hline $\begin{array}{l}\text { early African } \\
\text { H. erectus }\end{array}$ & 125 & 5,391 & 7.3 & 66.7 \\
\hline $\begin{array}{l}\text { early African } \\
\text { H. erectus }\end{array}$ & 300 & 12,937 & 10.6 & 97.9 \\
\hline Neanderthal & 25 & 1,049 & 3.6 & 32.6 \\
\hline Neanderthal & 125 & 5,245 & 7.2 & 65.9 \\
\hline $\begin{array}{l}\text { Neanderthal } \\
\text { early a.m. }\end{array}$ & 300 & 12,589 & 10.5 & 96.8 \\
\hline
\end{tabular}




\begin{tabular}{lrrcc}
$\begin{array}{l}\text { H. sapiens } \\
\text { early a.m. }\end{array}$ & 25 & 1,189 & 3.8 & 34.4 \\
$\begin{array}{l}\text { H. sapiens } \\
\text { early a.m. }\end{array}$ & 125 & 5,944 & 7.6 & 69.6 \\
\begin{tabular}{l} 
H. sapiens \\
\hline
\end{tabular} & 300 & 14,265 & 11.0 & 102.2 \\
\hline
\end{tabular}

stone tool making hominids at the beginning of the Lower Palaeolithic, are greater than those expected for a mammal of that body mass. One possible explanation is that the group sizes being sustained by this range area were also anomalously high. However, we must note a complicating factor. The maximum lithic transport distances reported for the European Middle Palaeolithic (c. 100 kilometres, Gamble, this volume) are in the order of magnitude characteristic for carnivore home ranges, and greatly in excess of those of a primate (cf. Table 8.8). The complication of dietary niche and trophic level as a determinant of range area, in addition to body mass and group size, must therefore be take into consideration when using these lithic transport data as information about group mass and ranging strategies (see Gamble and Steele, in prep., for a more extensive treatment of this data set and its associated problems).

In summary, Aiello and Dunbar (1993) have proposed an intriguing and original way of teasing socioecological information out of the palaeoanthropological record. This chapter, seen as a footnote to that work, proposes both an alternative prediction equation to get at the same behavioural variable, and a category of archaeological evidence which may complement the empirical literature on contemporary human groupings which has been used to date by Dunbar as an independent test of these predictions.

\section{ACKNOWLEDGEMENTS}

I am most grateful to Philip Prescott for help with the formulae for the RMA equation, and for deriving the formula for RMA residuals (Eq. 5).

\section{NOTE}

1 In a number of cases the group size averages extracted from the main source used by Dunbar (1992), which was Smuts et al. (1987), differed slightly from those which I estimated from the same data. In such cases, I have used the estimated mean group sizes given by Dunbar.

\section{REFERENCES}

Aiello, L.C. and Dunbar, R.I.M. (1993) 'Neocortex size, group size, and the evolution of language.' Current Anthropology 34:184-193.

Armstrong, E. (1985) 'Allometric considerations of the adult mammalian brain with 
special emphasis on primates.' In W.L.Jungers (ed.) Size and Scaling in Primate Biology, pp. 115-146. New York: Plenum.

Armstrong, E. (1990) 'Brains, bodies and metabolism.' Brain, Behavior and Evolution 36:166-176.

Ashton, E.H. and Spence, T.F. (1958) 'Age changes in the cranial capacity and foramen magnum of hominoids.' Proceedings of the Zoological Society of London 130:169181.

Blinkov, S.M. and Glezer, I.I. (1968) The Human Brain in Figures and Tables: A Quantitative Handbook. New York: Basic Books.

Borowsky, I.W. and Collins, R.C. (1989) 'Metabolic anatomy of brain: a comparison of regional capillary density, glucose metabolism, and enzyme activities.' Journal of Comparative Neurology 288:401-431.

Clutton-Brock, T.H. and Harvey, P.H. (1977) 'Primate ecology and social organization.' Journal of Zoology (London) 183:1-39.

Collins, R.C. (1991) 'Basic aspects of functional brain metabolism.' Ciba Foundation Symposia 163:6-22.

Davis, J.C. (1986) Statistics and Data Analysis in Geology, 2nd edn. New York: John Wiley and Sons.

Deacon, T.W. (1988) 'Human brain evolution II: embryology and brain allometry.' In H.Jerison and I.Jerison (eds) Intelligence and Evolutionary Biology, pp. 383-416. Berlin: Springer.

Draper, N.R. (1992) Straight Line Regression when Both Variables are Subject to Error. Technical Report No. 890, Dept of Statistics, University of Wisconsin, Madison, WI.

Dunbar, R.I.M. (1992) 'Neocortex size as a constraint on group size in primates.' Journal of Human Evolution 20:469-493.

Dunbar, R.I.M. (1993) 'Co-evolution of neocortex size, group size, and language in humans.' Behavioral and Brain Sciences 16:681-735.

Foley, R.A. (1987) Another Unique Species. Harlow: Longman.

Gamble, C.S. and Steele, J. (in prep.) 'Group mass and home range area of hominids: an archaeological evaluation of the group size debate.'

Grant, J.W.A., Chapman, C.A. and Richardson, K.S. (1992) 'Defended versus undefended home range size of carnivores, ungulates and primates.' Behavioral Ecology and Sociobiology 31:149-161.

Harvey, P.H., Martin, R.D. and Clutton-Brock, T. (1987) 'Life histories in comparative perspective.' In B.B.Smuts, D.L.Cheney, R.M.Seyfarth, R.W. Wrangham and T.T.Struhsaker (eds) Primate Societies, pp. 181-196. Chicago: University of Chicago Press.

Hassan, F.A. (1981) Demographic Archaeology. New York: Academic Press.

Hofman, M.A. (1989) 'On the evolution and geometry of the brain in mammals.' Progress in Neurobiology 32:137-158.

Janson, C.H. (1993) 'Primate group size, brains and communication: a New World perspective.' Behavioural and Brain Sciences 16:711-712.

McHenry, H.M. (1994) 'Tempo and mode in human evolution.' Proceedings of the National Academy of Sciences (USA) 91:6780-6786.

Mackinnon, J.R. (1974) 'The behaviour and ecology of wild orang-utans (Pongo pygmaeus).' Animal Behaviour 22:3-74.

Martin, R.D. (1989) Primate Origins and Evolution. London: Chapman and Hall.

Martin, R.D. and Barbour, A.D. (1989) 'Aspects of line-fitting in bivariate allometric analyses.' Folia Primatologica 53:65-81. 
Martin, R.D. and Maclarnon, A. (1988) 'Comparative quantitative studies of growth and reproduction.' Symposia of the Zoolological Society of London 60: 39-80.

Martins, E.P. (1993) 'Comparative studies, phylogenies and predictions of coevolutionary relationships.' Behavioural and Brain Sciences 16:714-716.

Napier, J.R. and Napier, P.H. (1985) The Natural History of the Primates. London: British Museum (Natural History)/Cambridge University Press.

Passingham, R.E. (1982) The Human Primate. San Francisco: Freeman.

Ross, C. (1992) 'Basal metabolic rate, body weight and diet in primates: an evaluation of the evidence.' Folia Primatologica 58:7-23.

Smith, R.J. (1994) 'Regression models for prediction equations.' Journal of Human Evolution 26:239-244.

Smuts, B.B., Cheney, D.L., Seyfarth, R.M., Wrangham, R.W. and Struhsaker, T.T. (eds) (1987) Primate Societies. Chicago: University of Chicago Press.

Stephan, H., Frahm, H. and Baron, G. (1981) 'New and revised data on volumes of brain structures in insectivores and primates.' Folia Primatologica 35:1-29.

Stern, N. (1993) 'The structure of the Lower Pleistocene archaeological record.' Current Anthropology 34:201-225. 